\title{
A Journey to Safe Motherhood in Pregnancy with Severe Cardiac Dysfunction- A Maternal Near Miss
}

\author{
Ruby Bhatia ${ }^{1}$, Sunita Mor ${ }^{2}$, Sajaad Manzoor ${ }^{3}$, Gaurav Aggarwal ${ }^{4}$, Neha Vashishat ${ }^{5}$
}

\begin{abstract}
${ }^{1}$ Department of Obstetrics and Gynaecology, Maharishi Markandeshwar Institute of Medical Sciences and Research, Deemed to be University, Mullana, Haryana, India. ${ }^{2}$ Department of Obstetrics and Gynaecology, Maharishi Markandeshwar Institute of Medical Sciences and Research, Deemed to be University, Mullana, Haryana, India. ${ }^{3}$ Department of Intervention Cardiology, Maharishi Markandeshwar Institute of Medical

Sciences and Research, Deemed to be University, Mullana, Haryana, India. ${ }^{4}$ Department of Cardiology, Maharishi Markandeshwar Institute of Medical Sciences and Research, Deemed to be University, Mullana, Haryana, India. ${ }^{5}$ Department of Obstetrics and Gynaecology, Maharishi Markandeshwar Institute of Medical Sciences and Research, Deemed to be University, Mullana, Haryana, India.
\end{abstract}

\section{INTRODUCTION}

Worldwide about 287,000 maternal deaths occur every year, and significant variation exists between low/high/middle-income populations.[1] Maternal death has direct and indirect causes. Indirect maternal deaths result from conditions existing before maternity or recently developed not related to maternity, e.g. cardiovascular diseases, HIV/AIDS, anaemia, infections. World Health Organization (WHO) outlined it as a condition within which "a woman nearly died, however survived throughout pregnancy, childbirth or within 42 days of termination of pregnancy, just by a chance or good hospital care." [2] Heart conditions presently represent the most common reason behind indirect maternal obstetrics deaths. Pregnancy is related to substantial and progressive hemodynamic changes beginning early in maternity, reaching their peak at the end of $2^{\text {nd }}$ trimester and remaining comparatively constant till child-birth. Major alterations in maternity include a 30 to 50 percent increase in blood volume and cardiac output and decreased blood pressure. In cardiac pregnant patients, these modifications might cause clinical decompensation, exposing these patients to probably life-threatening situations.[3] Here we represent a similar case of a maternal near miss due to severe cardiac dysfunction reported at 8 months amenorrhea.

Worldwide safe motherhood remains the main aim of Multispeciality antenatal care in every high-risk pregnancy. Primary is to prevent maternal near miss and overall maternal mortalities due to direct and indirect causes. Maternal near miss constitutes those pregnancies which survived a complication that occurred during pregnancy, childbirth or within 42 days of termination of pregnancy. ${ }^{[4]}$ Severe cardiac disease is in pregnancy is an important indirect cause of maternal near miss as well as maternal mortality.[2] We report a case of unbooked G2P1L1 26 year 33+4 weeks pregnancy with eclampsia HELLP syndrome jaundice severe anaemia with GRADE 4 cardiac disease: severe M. R severe TR moderate pericardial effusion moderate PAH with LVEF $<30 \%$ first visit reported at 8 months amenorrhoea. With the teamwork of skilled obstetrician and cardiology unit and frequent transfers from obstetrics to cardiology ICU patient delivered a healthy male with LSCS and discharged on postnatal day 15 on treatment.
Corresponding Author: Dr. Neha Vashishat, Department of Obstetrics and Gynaecology, MMIMSR, Mullana,

Haryana, India.

E-mail:drnehavashishat90@gmail.com

DOI: $10.14260 / j e m d s / 2020 / 83$

Financial or Other Competing Interests: None.

How to Cite This Article:

Bhatia R, Mor S, Manzoor S, et al. A journey to safe motherhood in pregnancy with severe cardiac dysfunction- a maternal near miss. J. Evolution Med. Dent. Sci. 2020;9(06):368-369, $10.14260 / \mathrm{jemds} / 2020 / 83$

Submission 01-12-2019,

Peer Review 17-01-2020,

Acceptance 22-01-2020,

Published 10-02-2020. 


\section{PRESENTATION OF CASE}

An unbooked G2P1L1 26-year-old at 8 months amenorrhoea came with severe breathlessness; tachycardia of 120 beats per minute; respiratory rate 38 cycles per minute BP 150/96 mmHg $\mathrm{SpO}_{2} 92 \%$ on room air with anasarca with decreased air entry in right chest with bilateral crepitation was admitted to MMIMSR emergency. She had persistent tachycardia and tachypnoea and patient was on cardiac monitoring. She had severe anaemia so her $\mathrm{Hb}$ was built up with 6 units PRBC transfusion. Dexamethasone $6 \mathrm{mg} 6$ hourly 4 doses were given for fetal lung maturity. Patient had an episode of eclamptic fit with HELLP Syndrome. Injection $\mathrm{MgSO}_{4}$ as per Pritchard's regimen started along with $\mathrm{O}_{2}$ inhalation with resuscitative measures initiated. Delivery was planned. Augmentation of labour with low dose concentrated injection oxytocin 2 units in $250 \mathrm{ml} \mathrm{RL}$ at 32 drops started. Patient became breathless with RR 34 per minute $\mathrm{SpO}_{2} 92 \%$ at room air BP 170/110 mmHg PR 124 per minute with bilateral chest full of crepts: A Maternal Near Miss. Patient was on continuous CTG monitoring. Per abdomen uterus became tense tender with non-reassuring FHS on CTG suggestive of abruptio placentae and HELLP syndrome, emergency LSCS done under general anaesthesia. Patient had eclampsia, HELLP syndrome, pulmonary oedema, abruptio placentae with fetal distress: most dreaded complication: A Maternal Near Miss. Patient developed DIC in intra operative period 10 units FFP, 6 units PRBCs and 4 units platelets were transfused. Live male baby weighing $1.9 \mathrm{~kg}$ with Apgar score of 7 and 9 at 1 and 5 minutes respectively at preterm gestation. Patient was most critical after Caesarean section and shifted to Cath CCU on ventilator. Bedside 2D ECHO depicted LVEF 20\% and all cardiac chambers were dilated so cardiologist took the decision of IABP for the patient and was done successfully. There she was managed with Lasix drip at $4 \mathrm{ml} / \mathrm{hr}$., heparin at $1.2 \mathrm{ml} / \mathrm{hr}$ and nor adrenaline which were then gradually tapered. Higher antibiotics started from post-operative day 4. Patient was managed securely with teamwork of skilled obstetrician and cardiologist of our institution. Patient was on ventilator support for 9 days. Patient passed a parasite on POD 6 in her stool and the sample was sent for parasitology examination.
After being on ventilatory support for 9 days with IABP in situ patient was discharged with healthy baby: A Journey to Safe Motherhood.

\section{CONCLUSIONS}

Severe Cardiac dysfunction grade 4 many a times is diagnosed first time in pregnancy. Grade 4 cardiac disease is a contraindication to pregnancy.[5-6] Unbooked pregnancy with severe cardiac dysfunction may report as maternal near miss in antenatal period. Safe motherhood initiative with early assessment of high-risk pregnancy and aggressive intervention through teamwork of skilled obstetrician, cardiologist and ICU team helped reduce severe acute maternal morbidity (SAMM) as well as maternal death and carry the pregnancy to safe motherhood with healthy mother and baby.

\section{REFERENCES}

[1] Say L, Chou D, Gemmill A, et al. Global causes of maternal death: a WHO systematic analysis. Lancet Glob Health 2014;2(6):e323-33.

[2] Roopa PS, Verma S, Rai L, et al. "Near miss" obstetric events and maternal deaths in a tertiary care hospital: an audit. Article ID 393758, J Pregnancy 2013;2013:1-5.

[3] Waksmonski CA, LaSala A, Foley MR. Acquired heart disease and pregnancy. Up To Date, 2014.

[4] Chhabra P. Maternal near miss: an indicator for maternal health and maternal care. Indian J Community Med 2014;39(3):132-7.

[5] Barberis VI. Cardiovascular disease and pregnancy: what to know: ESC Clinical Practice Guidelines on Management of Cardiovascular Diseases during Pregnancy. 2018.

[6] Bhatia R, Kaeley N, Bhatia R. Anaesthetic management of caesarean section in a term pregnancy with ventricular septal defect and pulmonary hypertension with severe pulmonary stenosis. J Clin Diagn Res 2016;10(6):UD03-4. 